\title{
Professional Learning Checklist for a Remote Delivery Format
}

\author{
David Fainstein, Cayla Lussier, Madison Cook, Virany Men \\ University of Oregon, USA
}

\begin{abstract}
The current global health crisis has thrust education into rapidly shifting the environment of practice from in-person to remote. It is incumbent on the internal support systems of education (e.g., inservice teacher training, instructional coaching) to seek avenues to continue supporting paraprofessionals, teachers, administrators, and allied professionals in schools because the compounding stress of pandemic health management, precarious working conditions, and personal demands are continuous and fluid. It may be most useful for educators to receive responsive and wellconsidered professional learning $(P L)$ with content relevant to the context of the current health crisis. PL practitioners' may adapt their existing content on evidence-based practices to suit the online environment (e.g., remote screening for early literacy skill development). Several considerations are provided for the adaptation of PL content, delivery, and participant feedback for the in-person-to-virtual delivery shift and are then synthesized into a checklist resource.
\end{abstract}

\section{Introduction}

Trainers, experts, coaches, and others providing knowledge translation found themselves in a position to quickly adapt content delivery methods throughout the global health crisis of 2020. While this content delivery adaptation took place across industries, it was perhaps the most arduous for those professional learners who work in a human service field (e.g., education, healthcare, social services) because of the lack of personal and co-located connection that is commonplace for in-person delivery. In education, we observed a global response to meet this need by providing guidance on an educational restart in September 2020 for the state, district, and school leadership teams as well as educators [1]. One notable challenge throughout planning the restart of school during a pandemic is determining best practices for the supporting agencies and people that provide professional learning (PL) opportunities to any level of school system stakeholders (e.g., paraprofessionals through administrative leadership). There are calls for the continuation of PL through virtual delivery for teachers; yet, there is a paucity of information on the necessary steps for virtual PL implementation that meets the needs of in-service educators [2].
Adapting in-person to online delivery of PL for educators includes a multitude of challenges. First, the prioritization that occurs when schools re-open is likely centered around the supports, processes, and personnel needed to have teachers provide instruction to students in a way that upholds personal health and safety and meets student needs for social, emotional, and academic growth. Note that this first priority does not explicitly tie in allied teacher supports (e.g., ongoing coaching, technical assistance), possibly because a safe and successful return to the learning environment for two groups, teachers and students, is of the highest importance. Second, the ubiquity of virtual PL for educators' lags behind that of other professions prior to the global health crisis of 2020 [2]. This may be a key underlying factor driving educators' needs because there is a lack of experience and norms for engaging in virtual PL in comparison to other industries. The acquisition of technologically based skills to engage, learn, and think critically in virtual environments can take considerable time and practice. Third, there are personal considerations (e.g., health and safety, family obligations, blurred personal-to-professional boundaries) for educators that necessarily supersede participation in PL opportunities. Acting as a caregiver, space constraints, and coping with an ongoing pandemic are just a few factors that complicate an already challenging landscape for everyone involved in virtual PL. Preliminary research from K-12 educational settings suggests that the transition from in-person to remote instruction is arduous enough to drive teachers towards avoidance coping strategies, burnout, and early retirement. The shift in educational delivery is no small feat; however, PL should not be positioned as an additive burden to an already challenging circumstance. Instead, PL can be positioned to act as a mitigating factor for educator burnout by providing direct and professional implementation support.

Despite the need for increasing teacher resources and support during a global health crisis, there is no substantial change to the decades of stagnated speed with which applicable, research-informed, and evidence-based practices in education are cultivated, refined, and disseminated. That is, we cannot accelerate the research-to-practice information pipeline by traditional means. Instead, we might look to theoretical frameworks that position researchers to 
write with the purpose of their audience broadening and enhancing understanding of effective educational practice [3]. This framework is a notable departure from the tips and tricks which are commonly shared online and through social media platforms. In short, Thomas Good states, "It must be kept in mind that the role of research is not to provide simple solutions for educators. The task of research is to broaden - not to narrow - teachers' conceptions of practice" (p.80). From this perspective, scholars point practitioners to empirically sound ideas, problems, and solutions that match the contemporary challenges that drive implementation frustrations.

\section{A PL Content Adaptation Framework}

At the intersection of learning sciences and instructional design fields, Hoadley and Van Haneghan [4] write that meaningful learning occurs when there is a focus on (p. 60):

- Conceptual understanding.

- Putting learning processes on par with teaching processes.

- Aiming for authenticity.

- Building on prior understanding and

- Providing opportunities for reflection.

The five areas above were derived from seminal work in instructional design and learning sciences [5], which formed a frame upon which PL for educators can be conceptualized. While the scope of applying PL in the current context through an instructional design framework may be taken from multiple perspectives, it is perhaps more productive to select a well-regarded conceptual framework that matches the need of the current context. That is, the pressing need is for PL practitioners to offer increasingly effective support to educator's because the external pressures on professionals in school buildings may continue to increase. Hoadley and Van Haneghan's conceptualization neatly categorizes PL practitioner and participant needs in a usable, intuitive manner for educators. This is partly due to their synthesis of learning sciences and instructional design, and partly due to their education-specific focus when detailing their framework. Further, their work is aligned with principles of explicit instruction (e.g., "building on prior understanding" matches "review prior skills and knowledge before beginning instruction"), which run in parallel as best practices in teaching and learning [6]. As such, five foci will act as a categorization tool and mechanism for elaborating practitioner considerations in a standalone checklist as a resource.

\subsection{Achieving Conceptual Understanding in PL}

The basis of this focus is the recent development in our collective understanding of human learning, which points to moving past the acquisition of facts and procedures and towards teaching the circumstances in which you can apply facts and procedures [5]. As applied to a PL virtual training context, several considerations emerge from the extant literature. Most notably, allocating time and energy to conceptualization, checking for understanding, removing barriers to clarifications, and real-world application were all important areas supported by the literature base [7].

\subsection{Putting Learning Processes on Par with Teaching Processes}

Several leading theorists in teaching and learning support the notion that instruction does not translate to learner conceptualization without active and participatory learning [8]. In fact, a recent position from the educational literature suggests that technology has increased the availability of active participatory learning through drastically heightened speed and modes of communication that were not previously possible at the conception of our theoretical understanding of how people learn [9]. Several areas that directly address and facilitate active participatory learning are addressed in this section of the checklist resource. Examples include ensuring that PL practitioners are modelling the virtual instructional process that they would want their own participants (e.g., teachers) to use with their clients (e.g., students) as well as building in participant expectations and role management while presenting.

\subsection{Aiming for Authenticity}

In comparison to the main five areas for the checklist resource, this focus is perhaps the most closely linked with addressing the current context because it suggests leaders in education are most effective when they present authentically with content that is of critical importance. The authenticity dimension spans both personal and professional bounds, as research in educational environments has demonstrated that being inattentive or unapproachable while presenting and contrived application activities, respectively, threaten the process of achieving positive learning, social, and psychological outcomes [10]. Therefore, the guiding questions in this focus are centered on building toward the positive outcomes for PL participants through moments of demonstrable authenticity, linking content with real-world situational factors that may require self-care or associated supports, and increased opportunities for interaction. 


\subsection{Building on Prior Understanding}

Similar to any PL opportunity, it is incumbent on the presenter to make a match between the content knowledge that the audience needs versus what they have already acquired [11]. Activating background knowledge is discussed at length in explicit instruction frameworks (e.g., see the work of Anita Archer and Charles Hughes [8]) and therefore serves as a good model for PL providers who are seeking to model evidence-based instruction in a virtual environment. The implications of explicitly addressing participant background knowledge, allowing time and space for participants to openly share their lived experience, and addressing misconceptions that exist amongst the audience are the primary areas addressed in the guiding questions for this focus area.

\subsection{Providing Opportunities for Reflection}

Based on the seminal work for Sawyer [5], offering multiple opportunities for PL participant's to express their emerging knowledge increases the likelihood of knowledge translation into conceptualization and skills for learners. This focus is highly related to Putting Learning Processes on Par with Teaching Processes that emphasizes active participatory learning; though, the reflective opportunities in this focus are more distal from the content learned. Specifically, having participants reflect on their previous practice (e.g., teaching, administration, intervention) as it compares and contrasts to the content presented in a PL session (e.g., using evidence-based instructional routines, adapting prior practices to new virtual tools) is the core focus presented through guiding questions in the checklist resource.

\section{Discussion and Future Directions}

The purpose of this document and supplemental resource is to leverage a research-informed perspective on best practices in delivering PL during an amalgamation of transformative factors (e.g., educational disruption, global health crisis, societal unrest). In order to develop the checklist resource for the current project, a rationale and framework are developed from existing literature that has deep roots in decades of research on how to teach people such that they learn effectively. Education, as a sector of human services, was not prepared for an immediate pivot to virtual delivery from pre-pandemic times. Given that other sectors (e.g., medical, engineering, university, and similar higher education institutions) hold potential to offer insights on professional development activities that are effective across domains, the literature was scanned broadly to fit in best-practices across industries with the selected theoretical framework initially described by Sawyer [5] and elaborated by Hoadley and Van Haneghan [4]. Together, authors have focused on interactivity, learner preference, or even broader aspects of online PL in contexts outside of education (e.g., primarily medical settings) [12], [14]. The packaging and alignment of these best practices into a cohesive checklist serve the purpose of broadening PL provider considerations ahead of delivering content virtually in the current context.

Due to the immediacy of resources required to offer continuity of support systems for professionals in education, it was necessary to focus on broadening instructor's conception of practice as opposed to a more formalized, systematic method of altering PL provider practice (e.g., fidelity checks, rating and feedback systems for continuous improvement). However, it is entirely possible to formalize and alter the supplemental checklist resource herein such that it is more closely tied to a self-assessment of PL provider implementation. Before making this iterative change, there are several considerations in taking the existing checklist resource and iterating or formalizing. First, the five foci may need to be reconsidered and even studied quantitatively (e.g., using confirmatory factor analysis methods) to confirm that Sawyer's [5] key foci represent cohesive constructs that help to elucidate primary areas for adjustments to PL practice. Second, it will be imperative to review and include impending research on the educational supports that teachers, paraprofessionals, administrators, allied professionals, students, families, volunteers, community members, and even broader stakeholders in an educational ecosystem require. The reflection focus, for example, may require additional fine-tuning as we learn more about what is and is not appropriate to reflect on given the rapidly shifting environments that educators must navigate (i.e., some environments may not be comfortable to return to reflect on; though, there is no research to support this idea yet). Third, education is uniquely positioned to thoroughly iterate on the checklist resource herein because of the applicability of the content to teacher practice. That is, an exemplary PL session may contain many of the same elements as an exemplary teacher lesson for secondary school students (e.g., teaching with authenticity, leveraging prior understanding, teaching to conceptual understanding). Further work on this checklist resource may be as straightforward as asking teachers for feedback (e.g., which guiding questions on the checklist offered you novel insights? Which guiding questions would you change or add?) and iteratively improving the resource for a broader net of PL practitioners.

The intention of the authors is to provide an opensource, free draft of a checklist to support PL practitioners in their work. The uptake or continuity 
of remote trainings post-pandemic is unknown; yet, the appeal of efficiency in time and money is clear. There is an understood "magic in the room," when PL trainers and trainees are co-located, and this is one potential reason why educators have yet fully adopt one specific preferred format for PL. Indeed, some balance of remote and in-person PL may be optimal for most educators. One critical element of PL in any format is including a continuous improvement cycle [15]. Checklists are well-positioned to act as a catalyst in a continuous improvement process for PL. There is perhaps a lower value judgement associated with checklist outcomes than rating-system (e.g., "rate the PL provider's performance on a Likert scale") or qualitative feedback (e.g., "tell us what you would improve about this training") as outcomes. One might be best served using a checklist to ensure that there are no areas in a blind spot of effective PL delivery (e.g., taking time to authentically connect with your audience). The breadth of the five areas of foci in the checklist are ideally broad enough to capture a complete view that is relevant to continuously improving the design and delivery of PL.

\section{Conclusion}

As a beginning, we offer a research-informed, checklist tool to support professional learning staff in their efforts to support educators acquire, use, and refine new instructional techniques. This tool requires validation and we anticipate psychometric properties on the initial draft will speak to modifications of the checklist.

\section{References}

[1] Melnick H. and Darling-Hammond, L. (2020). Reopening Schools in the Context of COVID-19: Health and Safety Guidelines from Other Countries. Policy Brief. Learning Policy Institute.

[2] Vislosky E. and Hunziker, J. (2020). "Regional Educational Laboratory Program (REL): Ask A REL," RELevant Viewpoints and Findings from the REL Mid-Atlantic. https://ies.ed.gov/ncee/edlabs/regions/midatlantic/ app/Blog/Post/1034, September. (Access Date: 7 February 2021)

[3] Good, T. (1989). Classroom and School Research: Investments in Enhancing Schools. Laboratory Policy Paper.

[4] C. Hoadley and J. P. Van Haneghan, "The learning sciences: Where they came from and what it means for instructional designers," Trends Issues Instr. Des. Technol. 3rd Ed Pp 53-63 N. Y. Pearson, 2011.

[5] Sawyer, R. K. (2006). "The new science of learning," Camb. Handb. Learn. Sci., vol. 1, p. 18.
[6] Hammond L. and Moore, W. M. (2018). "Teachers Taking Up Explicit Instruction: The Impact of a Professional Development and Directive Instructional Coaching Model," Aust. J. Teach. Educ., vol. 43, no. 7, pp. 110-133, July. https://eric.ed.gov/?id=EJ1188027. (Access Date: 21 Sept-ember 2020).

[7] Gegenfurtner, A. Zitt, A. and Ebner, C. (2020). "Evaluating webinar-based training: a mixed methods study of trainee reactions toward digital web conferencing," Int. J. Train. Dev., vol. 24, no. 1, pp. 5-21, DOI: 10.1111/ijtd.12167.

[8] Archer A. L. and Hughes, C. A. (2010). Explicit instruction: Effective and efficient teaching. Guilford Press.

[9] Cunningham, C. A. (2009). "Transforming Schooling through Technology: Twenty-First-Century Approaches to Participatory Learning," Educ. Cult., vol. 25, no. 2.

[10] Keller, M. M. Becker, E. S. Frenzel, A. C. and Taxer, J. L. (2018). "When Teacher Enthusiasm Is Authentic or Inauthentic: Lesson Profiles of Teacher Enthusiasm and Relations to Students' Emotions," AERA Open, vol. 4, no. 2. https://eric.ed.gov/?id=EJ1194135 (Access Date: 26 September 2020).

[11] Linder, R. A. Post, G. and Calabrese, K. (2012). "Professional Learning Communities: Practices for Successful Implementation," Delta Kappa Gamma Bull., vol. 78, no. 3, p. 13, April. https://www.questia.com/lib rary/journal/1P3-2725899881/professional-learning-comm unities-practices-for-successful Access Date: 26 September 2020).

[12] Lieser, P. Taf, S. D. and Murphy-Hagan, A. (2018). "The Webinar Integration Tool: A Framework for Promoting Active Learning in Blended Environments," J. Interact. Media Educ., vol. no. 1, https://eric. ed.gov/?id=EJ1180364. (Access Date: 22 September 2020).

[13] Javorcik T. and Polasek, R. (2018). "The Basis for Choosing Microlearning Within the Terms of E-Learning in the Context of Student Preferences," in 2018 16th International Conference on Emerging eLearning Technologies and Applications (ICETA), Nov. pp. 237244, DOI: 10.1109/ICETA.2018.8572183.

[14] Toquero C. M. and Talidong, K. J. (2020). "Webinar Technology: Developing Teacher Training Programs for Emergency Remote Teaching amid COVID-19," Interdiscip. J. Virtual Learn. Med. Sci., vol. 11, no. 3, pp. 200-203, Sep. DOI: 10.30476/ijvlms.2020.86889 .1044.

[15] Quay S. and Lockwood. M. (2019). "Sustaining a Continuous Improvement Culture in Educator Preparation: A Higher Education Network Based on Data Wise." Journal of Practitioner Research vol. 4, no. 1, pp. 1- 19. DOI: 10.5038/2379-9951.4.1.1092. 


\section{Virtual PL Checklist for Practitioners during COVID-19}

The following checklist is intended to guide practitioners toward broadening their practice as they work with educators to include meaningful, authentic, and high-quality professional learning experiences in a virtual context. The domains embedded within this checklist are intended to organize reflective and responsive practice, and not serve as definitive constructs.

Examine each guiding question and consider if you are incorporating that key idea(s) into your PL practice or if those ideas can be improved upon through iterative change:

\begin{tabular}{|c|c|}
\hline Domain & Guiding Questions \\
\hline \multirow{6}{*}{$\begin{array}{l}\text { Conceptual } \\
\text { Understanding }\end{array}$} & $\begin{array}{l}\text { Do participants have sufficient time to conceptualize } \\
\text { the content within or between sessions? }\end{array}$ \\
\hline & $\begin{array}{l}\text { Will participants have the opportunity to check their } \\
\text { understanding of the content proximally and distally } \\
\text { from initial presentation? }\end{array}$ \\
\hline & $\begin{array}{l}\text { Are there impediments that limit participant's ability to } \\
\text { ask clarifying questions virtually? How can those } \\
\text { barriers be addressed to maximize engagement? }\end{array}$ \\
\hline & $\begin{array}{l}\text { Can we increase the opportunities for participant } \\
\text { application of concepts to real-world scenarios within } \\
\text { and between sessions? }\end{array}$ \\
\hline & $\begin{array}{l}\text { Are there virtual tools embedded to provide direction } \\
\text { or feedback on participant application of session } \\
\text { content? }\end{array}$ \\
\hline & $\begin{array}{l}\text { Are the virtual resources that supplement content } \\
\text { learning accessible to all participants? }\end{array}$ \\
\hline \multirow{6}{*}{$\begin{array}{l}\text { Instructional } \\
\text { Processes }\end{array}$} & $\begin{array}{l}\text { Does the audience have multiple opportunities for } \\
\text { active engagement? Examples include polls, breakout } \\
\text { rooms, }\end{array}$ \\
\hline & $\begin{array}{l}\text { If participants want to share or repurpose your content } \\
\text { for their local context, will they have sufficient access to } \\
\text { materials that you used to put the training or content } \\
\text { together? }\end{array}$ \\
\hline & $\begin{array}{l}\text { Do you include a moderator or facilitator who } \\
\text { concurrently organizes content delivery with you? }\end{array}$ \\
\hline & $\begin{array}{l}\text { Will the moderator or facilitator anticipate moments } \\
\text { where the audience may need review, additional } \\
\text { practice, or further resources? }\end{array}$ \\
\hline & $\begin{array}{l}\text { Does your audience know the exact expectations (e.g., } \\
\text { camera on/off, when to ask questions, breakout room } \\
\text { formats) before, during, and after a session? }\end{array}$ \\
\hline & $\begin{array}{l}\text { Which methods from your presentation delivery would } \\
\text { you want your audience to replicate if they used your } \\
\text { content as a training at their local site? }\end{array}$ \\
\hline
\end{tabular}




\begin{tabular}{|c|c|c|}
\hline \multirow{5}{*}{ Authenticity } & & $\begin{array}{l}\text { Do you share elements of your lived experience } \\
\text { virtually (through story or media) to demonstrate } \\
\text { authenticity to your participants? }\end{array}$ \\
\hline & $\square$ & $\begin{array}{l}\text { Are the specific online tools that you can incorporate to } \\
\text { increase the likelihood of authentic participant } \\
\text { engagement (e.g., polls, anonymous sharing via text or } \\
\text { chat)? }\end{array}$ \\
\hline & $\square$ & $\begin{array}{l}\text { Do you plan on acknowledging the current context of } \\
\text { COVID-19 and how your content applies within this } \\
\text { context? }\end{array}$ \\
\hline & $\square$ & $\begin{array}{l}\text { Do you plan on acknowledging other factors that may } \\
\text { interact with the emotional presence of your audience } \\
\text { (e.g., significant local circumstances, weather-related } \\
\text { issues, land acknowledgement, Zoom fatigue)? }\end{array}$ \\
\hline & $\square$ & $\begin{array}{l}\text { Are you allotting time and activities for rapport } \\
\text { development depending on the pre-established } \\
\text { relationship with participants? That is, a novel } \\
\text { audience relationship may require more time or virtual } \\
\text { activities to develop rapport. }\end{array}$ \\
\hline \multirow{4}{*}{$\begin{array}{l}\text { Leveraging Prior } \\
\text { Understanding }\end{array}$} & $\square$ & $\begin{array}{l}\text { What background knowledge is necessary to } \\
\text { conceptualize content in your session? Is this } \\
\text { communicated to your audience in advance? }\end{array}$ \\
\hline & $\square$ & $\begin{array}{l}\text { Which elements of prior understanding (e.g., technical } \\
\text { knowledge, lived experience) do you intend on } \\
\text { explicitly addressing for participants within the } \\
\text { session? }\end{array}$ \\
\hline & $\square$ & $\begin{array}{l}\text { Do you intend on having participants discuss how their } \\
\text { background knowledge and prior experiences interact } \\
\text { with the material that you are presenting during your } \\
\text { session? }\end{array}$ \\
\hline & $\square$ & $\begin{array}{l}\text { Are there any potential misconceptions situated in } \\
\text { participants' background knowledge that may be worth } \\
\text { exploring in your session? }\end{array}$ \\
\hline \multirow{4}{*}{ Reflection } & $\square$ & $\begin{array}{l}\text { Is there time protected during or after your session } \\
\text { content for participants to reflect on their learning? }\end{array}$ \\
\hline & $\square$ & $\begin{array}{l}\text { Do you prompt participants to engage in meaningful } \\
\text { reflection with specific questions or statements? }\end{array}$ \\
\hline & $\square$ & $\begin{array}{l}\text { Are you able to model any of your own reflective } \\
\text { techniques given the current context (e.g., removing } \\
\text { "screen time" to reflect on practice with pen and } \\
\text { paper)? }\end{array}$ \\
\hline & $\square$ & $\begin{array}{l}\text { Is there an opportunity for participants to reflect on the } \\
\text { malleable factors (e.g., practice, prioritization, feedback } \\
\text { use) that drive the change you want them to make (e.g., } \\
\text { increase self-care, differentiate instructional routines)? }\end{array}$ \\
\hline
\end{tabular}

